\title{
Study on the Electrochemical Performance of Sacrificial Anode Interfered by Alternating Current Voltage
}

\author{
Qingmiao Ding $(\mathbb{D}$, Xiao Chu $(\mathbb{D}$, Tao Shen $(\mathbb{D}$, and Xiaoxiao Yu \\ Airport College, Civil Aviation University of China, Tianjin, China \\ Correspondence should be addressed to Xiao Chu; xchu@cauc.edu.cn
}

Received 4 July 2018; Revised 21 September 2018; Accepted 14 October 2018; Published 5 November 2018

Academic Editor: Ramazan Solmaz

Copyright (C) 2018 Qingmiao Ding et al. This is an open access article distributed under the Creative Commons Attribution License, which permits unrestricted use, distribution, and reproduction in any medium, provided the original work is properly cited.

\begin{abstract}
The effect of alternating current $(\mathrm{AC})$ voltage of $0 \mathrm{~V}, 1 \mathrm{~V}, 3 \mathrm{~V}$, and $5 \mathrm{~V}$ on magnesium alloy sacrificial anode electrochemical properties was studied by open circuit potential (OCP) analysis, electrochemical impedance spectroscopy (EIS), and polarization curve measurements. The results demonstrate that the AC voltage has a great effect on the magnesium alloy sacrificial anode. The corrosion control is anode control in the first two days with no AC interference. The stray current accelerates the transmission and diffusion of oxygen, so the corrosion rate under $\mathrm{AC}$ interference is higher than that with no $\mathrm{AC}$ interference. And the corrosion control becomes cathodic control under AC interference. The corrosion rate of the sacrificial anode is faster and faster as the AC interference voltage increases in the range of $0 \sim 5 \mathrm{~V}$, while the corrosion inclination is weakened.
\end{abstract}

\section{Introduction}

It has been known that the AC stray current has a great influence on the potential and current of the buried metallic pipeline when it is close to high voltage $\mathrm{AC}$ transmission lines or rail transit systems $[1,2]$. Moreover, the presence of AC has caused serious damage on interfered metallic structures even when cathodic protection is applied [2-5]. L. Y. Xu [6] found that the presence of $\mathrm{AC}$ interference decreased the $\mathrm{CP}$ effectiveness to protect the steel from corrosion. Only when $\mathrm{CP}$ potential was sufficiently negative, the steel was under a complete protection even when the AC current density was $400 \mathrm{~A} / \mathrm{m}^{2}$. The cathodic protection system of airport apron pipe network generally adopts magnesium alloy sacrificial anode cathodic protection [7], and it also inevitably has an adverse effect on the sacrificial anode performance $[8,9]$.

As early as 1978, Pookote [10] pointed out that AC could lead to the potential shift of $\mathrm{Mg}$ sacrificial anode and accelerate its dissolution. Freiman [11] found that the potential of $\mathrm{Mg}$ sacrificial anode shifted positively under AC and the current efficiency of $\mathrm{Mg}$ was decreased significantly. For pipelines protected by sacrificial anodes, excessive AC interference voltage could degrade the performance of the sacrificial anode, shorten its service life, and even "polarity reversal" which could accelerate the corrosion of the pipeline [12]. Bruchner [13] found that the polarity of pipeline- $\mathrm{Mg}$ sacrificial anode turned to be the cathode while the protected pipeline turned to be the anode when the applied AC current density reached $39 \mathrm{~A} / \mathrm{m}^{2}$. Dezhi Tang [14] found that the output cathodic protection current of the $\mathrm{Mg}$ sacrificial anode decreased at alternating current density of $50 \mathrm{~A} / \mathrm{m}^{2}$. Polarity reversal occurred to $\mathrm{Mg}$ sacrificial anode as soon as alternating current interference of $100 \mathrm{~A} / \mathrm{m}^{2}$ (or larger) was applied. Yin Kehua et al. [15] studied the effects of AC interference on the properties of $\mathrm{Mg}, \mathrm{Al}$, and $\mathrm{Zn}$ sacrificial anodes in soil. The results showed that with the increase of AC interference, the output negative current density of $\mathrm{Mg}$ and $\mathrm{Al}$ would decrease continuously, while output current density of $\mathrm{Zn}$ was relatively stable. At the same time, the "polar reversal" behavior of $\mathrm{Mg}$ anode under $\mathrm{AC}$ interference was also observed.

In summary, AC voltage can interfere in the normal operation of cathodic protection system $[9,16-21]$, or cause polarity reversal in pipelines with the sacrificial anode, 


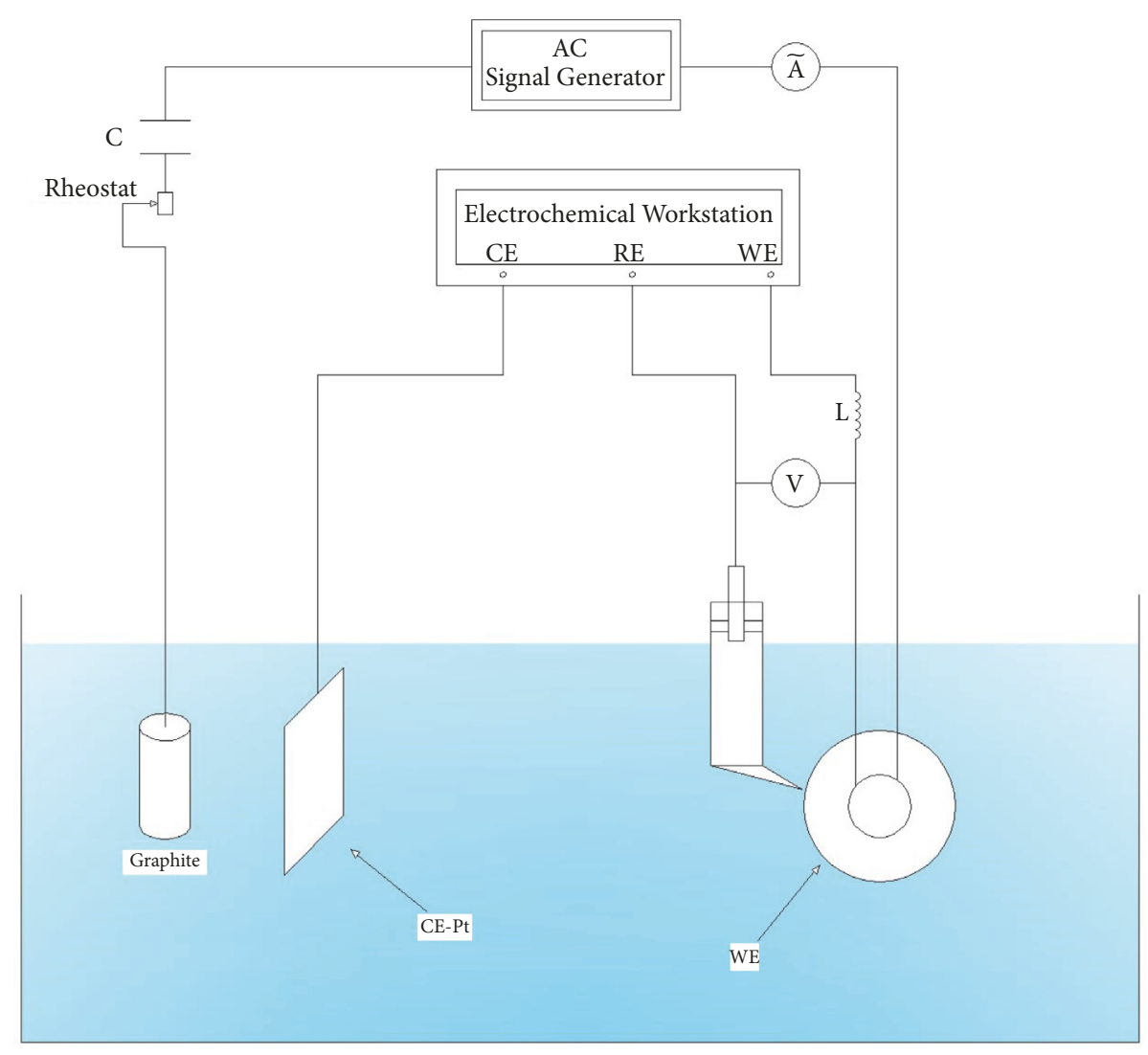

FIGURE 1: Schematic diagram of the experimental.

leading to the pipeline lack of effective protection. Therefore, it is very necessary to study the influence of AC stray current on the cathodic protection system.

\section{Experimental Procedure}

2.1. Specimen and Solution. Sacrificial anode specimens used in this work were magnesium alloy rods with diameter of $10 \mathrm{~mm}$. The chemical composition of magnesium alloy rods is as follows: $6.5 \mathrm{wt} \% \mathrm{Al}, 3.5 \mathrm{wt} \% \mathrm{Zn}, 0.6 \mathrm{wt} \% \mathrm{Mn}, 0.005$ wt $\% \mathrm{Fe}, 0.003$ wt $\% \mathrm{Ni}, 0.02 \mathrm{wt} \% \mathrm{Cu}, 0.1 \mathrm{wt} \% \mathrm{Si}$, and bal. $\mathrm{wt} \% \mathrm{Mg}$. The magnesium alloy sacrificial anode rods were welded with wires and put into the electrician tubes. We used epoxy resin and curing agent mixture with the ratio of 3:1 to pour magnesium alloy sacrificial anode rods, leaving an exposure area as the working face. The electrode was ground sequentially to 2000grit emery paper and then cleaned by acetone, absolute ethanol, and distilled water.

The test solution was brought from the soil along the apron with the chemical composition of $\mathrm{Na}_{2} \mathrm{CO}_{3} 0.1599 \mathrm{~g} / \mathrm{L}$, $\mathrm{NaCl} 0.5124$ g/L, $\mathrm{Na}_{2} \mathrm{SO}_{4} 0.1712 \mathrm{~g} / \mathrm{L}, \mathrm{NaHCO}_{3} 0.0864 \mathrm{~g} / \mathrm{L}$. All measurements were conducted at ambient temperature of $20^{\circ} \mathrm{C}$ and open to air.

2.2. Electrochemical Equivalent Circuit for the Experimental. Figure 1 shows the schematic diagram of the experimental set-up for studies of AC interference corrosion under different chloride ion concentration or test temperature. The experimental device uses a three-electrode system. The magnesium alloy sacrificial anode rod was used as the working electrode (WE), the platinum electrode was used as the counter electrode (CE), and a saturated calomel electrode (SCE) was used as a reference electrode (RE). The distance between WE and RE was about $2 \mathrm{~mm}$, in order to reduce the ohmic drop in potential measurements. The electric circuit was specially designed to supply and measure AC and DC signals independently. Working electrode, AC power source, capacitor, and carbon rod form an AC interference system. Reference electrode, high resistance voltmeter, and working electrode compose voltage test system. Auxiliary electrode, reference electrode, working electrode, and electrochemical workstation consist of electrochemical test system. In this work, the sinusoidal AC signal with a frequency of $50 \mathrm{~Hz}$ was supplied between two graphite electrodes. Within the AC mesh, an electrolytic capacitor $(50 \mathrm{~V}, 470 \mu \mathrm{F})[1]$ in series was used to prevent DC circulation. And within the DC mesh, an inductor [2] was used to prevent the flow of AC current into the electrochemical measurement system.

2.3. Electrochemical Measurements. The electrochemical workstation (CHI660D) used a three-electrode cell system. Specimens used for electrochemical measurements were coated with epoxy resin, leaving an exposure area of 3.925 $\mathrm{cm}^{2}$ as the working surface. The electrode was ground 


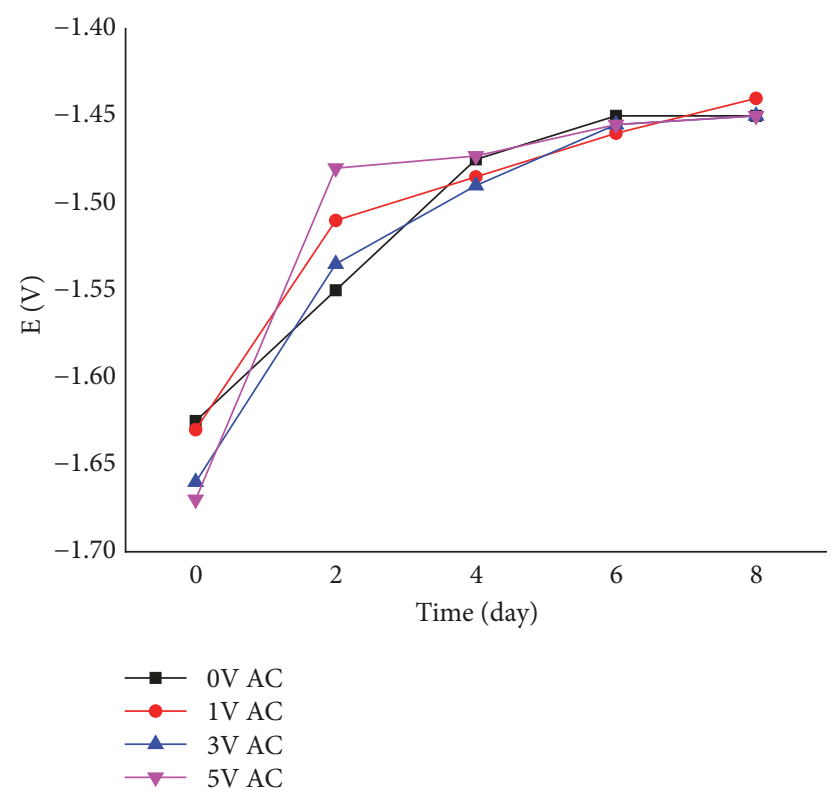

FIGURE 2: The open circuit potential of magnesium sacrificial anode under different $\mathrm{AC}$ interference voltages at an ambient temperature of $20^{\circ} \mathrm{C}$ in the test solution.

sequentially to 2000 grit emery paper and then cleaned by acetone, anhydrous alcohol, and distilled water.

The stable open potential, electrochemical impedance spectroscopy, and polarization curves of magnesium alloy sacrificial anode were measured by the electrochemical workstation every day. The frequency range of EIS was $100 \mathrm{kHz}$ to $0.1 \mathrm{~Hz}$ while the amplification of sinusoidal AC signal was $3 \mathrm{mV}$. The data analysis software was ZSimpWin3.21. According to the test results of open circuit potential, it was determined that the range of polarization curve was from $0.8 \mathrm{~V}$ to $-0.3 \mathrm{~V}$, and the scanning rate was $0.1667 \mathrm{mV} / \mathrm{s}$.

\section{Results}

Figure 2 shows the open circuit potential of sacrificial anode under various $\mathrm{AC}$ voltages at an ambient temperature of $20^{\circ} \mathrm{C}$ in the test solution for eight days. The corrosion potential of the magnesium sacrificial anode was observed to shift positively under all experimental conditions. It indicated that the activity in the sacrificial anode surface decreased as time went by with or without AC interference. The open circuit potential's positive migration under $\mathrm{AC}$ interference of $5 \mathrm{~V}$ voltage was the maximum while that of $0 \mathrm{~V}$ voltage was the minimum.

Table 1 shows the corrosion electrochemical parameters fitted by polarization curves of the sacrificed anode under different $\mathrm{AC}$ interference voltages of $0 \mathrm{~V}, 1 \mathrm{~V}, 3 \mathrm{~V}$, or $5 \mathrm{~V}$. The polarization resistance increased gradually and the corrosion current decreased with the progress of the experiment. It indicated that the corrosion tendency and rate of the sacrificial anode decreased with the increasing of the experimental time. Compared with the polarization resistance and corrosion current at the same experiment time, it could be seen that the polarization resistance was smaller under AC interference than that without AC interference, and the corrosion current was larger than that without AC interference. It indicated that $\mathrm{AC}$ interference voltage could reduce the corrosion tendency of the sacrificial anode while it would accelerate the dissolution rate of magnesium anodic. The larger the AC interference voltage was, the stronger the promotion effect was.

Sacrificial anode control could be observed by the slope trend of the cathode and anode polarization curves. At the beginning of the experiment, the slope of cathodic polarization curve was larger than that of anodic polarization curve. After a certain period of experiment, the slope of anodic polarization curve was gradually higher than that of cathodic polarization curve. It indicated that the cathode control gradually transformed into anode control. It showed that AC played an important role in anodic polarization of magnesium alloy sacrificial anode.

Figure 3 shows the EIS under different AC in the original soil simulation solution and at ambient temperature. It could be seen that there were two impedance arcs in the shape of EIS under the four environments of $0 \mathrm{~V}, 1 \mathrm{~V}, 3 \mathrm{~V}$, and $5 \mathrm{~V}$ AC interference voltages. The change of the impedance arc was the largest on the second day of experiment. The variation of impedance arc became smaller with the lapse of time. We could find that the radius of impedance arc represented by the sacrificial anode surface corrosion products was the largest with no AC. And the larger the AC interference was, the larger the radius of impedance arc was. It indicated that AC interference accelerated the corrosion of the sacrificial anode and promoted the corrosion products on the surface of sacrificial anode. The greater the AC interference was, the faster the rate of corrosion was.

In order to analyze the sacrificial anodic corrosion process, the EIS of Figure 2 is fitted with the equivalent circuits. Figure 4 shows the equivalent circuit of the EIS of the magnesium alloy sacrificial anode during the experiment. The elements represented different physical meanings: Rs represented the resistance of the solution, CPEdl represented the electric double layer capacitor of the metal oxide film and the solution, CPE represented the capacitance due to the ion through surface oxide film, Rt represented the charge transfer resistance, and Rc represented the oxidation resistance. When the experiment started, the oxide film on the surface of the sacrificial anode was destroyed, and the exposing metal reacted with oxygen. The corrosion products began to accumulate on the surface of the sacrificial anode. The physical meaning of the element representation changed: Rs still represented the resistance of the solution and CPEdl still represented the electric double layer capacitor of the metal oxide film and the solution, and CPE no longer expressed the capacitance due to the ion through surface oxide film, but on behalf of the capacitance due to the ion through corrosion scale. Rt still represented the charge transfer resistance. Rc represented the corrosion product film resistance.

Figure 5 shows the process of the change of corrosion product film resistance Rc under different AC interference voltages. It could be seen that the value of $\mathrm{Rc}$ increased gradually as experiment time went by. The larger the AC voltage was, the greater the change of Rc was. 
TABLE 1: The corrosion electrochemical parameters from polarization curves of the sacrificed anode under different AC voltages.

\begin{tabular}{|c|c|c|c|c|c|c|}
\hline $\begin{array}{l}\mathrm{AC} \\
\text { voltage }\end{array}$ & $\begin{array}{c}\text { Electrochemical } \\
\text { parameters }\end{array}$ & $0 \mathrm{~d}$ & $2 d$ & $4 \mathrm{~d}$ & $6 \mathrm{~d}$ & $8 \mathrm{~d}$ \\
\hline \multirow{4}{*}{$0 \mathrm{~V}$} & $\begin{array}{l}\text { Polarization } \\
\text { resistance } \\
(\Omega)\end{array}$ & 659.3 & 731.1 & 820.4 & 940.8 & 1018.2 \\
\hline & $\begin{array}{c}\text { Corrosion current } \\
\text { (A) }\end{array}$ & $6.530 * 10^{-5}$ & $5.825 * 10^{-5}$ & $5.167 * 10^{-5}$ & $4.072 * 10^{-5}$ & $3.876 * 10^{-5}$ \\
\hline & $\begin{array}{l}\text { Cathodic } \\
\text { Tafel slope }\end{array}$ & 6.340 & 5.813 & 5.082 & 4.458 & 5.049 \\
\hline & $\begin{array}{c}\text { Anodic } \\
\text { Tafel slope }\end{array}$ & 3.760 & 4.396 & 5.175 & 5.174 & 5.97 \\
\hline \multirow{4}{*}{$1 \mathrm{~V}$} & $\begin{array}{c}\text { Polarization } \\
\text { resistance } \\
(\Omega)\end{array}$ & 243.2 & 346.4 & 592.4 & 724.8 & 785 \\
\hline & $\begin{array}{c}\text { Corrosion current } \\
\text { (A) }\end{array}$ & $1.814 * 10^{-4}$ & $1.279 * 10^{-4}$ & $7.558 * 10^{-5}$ & $5.858 * 10^{-5}$ & $5.602 * 10^{-5}$ \\
\hline & $\begin{array}{l}\text { Cathodic } \\
\text { Tafel slope }\end{array}$ & 5.021 & 4.788 & 4.621 & 4.413 & 4.774 \\
\hline & $\begin{array}{c}\text { Anodic } \\
\text { Tafel slope }\end{array}$ & 4.834 & 5.027 & 5.091 & 5.826 & 5.113 \\
\hline \multirow{4}{*}{$3 \mathrm{~V}$} & $\begin{array}{l}\text { Polarization } \\
\text { resistance } \\
(\Omega)\end{array}$ & 331.7 & 488.8 & 510.3 & 595.8 & 623.5 \\
\hline & $\begin{array}{c}\text { Corrosion current } \\
\text { (A) }\end{array}$ & $1.254 * 10^{-4}$ & $8.871 * 10^{-5}$ & $7.968 * 10^{-5}$ & $7.5 * 10^{-5}$ & $7.253 * 10^{-5}$ \\
\hline & $\begin{array}{l}\text { Cathodic } \\
\text { Tafel slope }\end{array}$ & 5.376 & 4.775 & 4.829 & 4.027 & 4.017 \\
\hline & $\begin{array}{c}\text { Anodic } \\
\text { Tafel slope } \\
\end{array}$ & 4.894 & 5.211 & 5.864 & 5.703 & 5.597 \\
\hline \multirow{4}{*}{$5 \mathrm{~V}$} & $\begin{array}{c}\text { Polarization } \\
\text { resistance } \\
(\Omega)\end{array}$ & 228.5 & 245.3 & 298.7 & 378.2 & 431.6 \\
\hline & $\begin{array}{c}\text { Corrosion current } \\
\text { (A) }\end{array}$ & $1.914 * 10^{-4}$ & $1.818 * 10^{-4}$ & $1.476 * 10^{-4}$ & $1.178 * 10^{-4}$ & $9.838 * 10^{-5}$ \\
\hline & $\begin{array}{l}\text { Cathodic } \\
\text { Tafel slope }\end{array}$ & 5.238 & 4.694 & 4.701 & 4.814 & 3.880 \\
\hline & $\begin{array}{c}\text { Anodic } \\
\text { Tafel slope }\end{array}$ & 4.708 & 5.052 & 5.222 & 4.951 & 6.359 \\
\hline
\end{tabular}

\section{Discussion}

During the corrosion of magnesium alloy sacrificial anode in the soil simulated solution, the anodic and cathodic reactions include $\mathrm{Mg}$ oxidation and the reduction of hydrogen ions, respectively:

$$
\begin{aligned}
\mathrm{Mg} & \longrightarrow \mathrm{Mg}^{2+}+2 \mathrm{e} \\
2 \mathrm{H}^{+}+2 \mathrm{e} & \longrightarrow \mathrm{H}_{2}
\end{aligned}
$$

Generally, the presence of alternating current in the soil around the buried pipelines is prevalent. And it has been acknowledged that buried pipelines corrode at an accelerated rate in the presence of AC interference. Magnesium alloy is a more reactive metal than carbon steel, and AC should have a greater impact on the sacrificial anode. So when
AC interference is applied (on the 0th day), the potential is negatively shifted. And the greater the AC interference voltage is, the greater the potential offset is. Because of the AC interference, magnesium dissolution is accelerated. The corrosion product $\mathrm{Mg}^{2+}$ does not diffuse in time; this would cause a local saturation of $\mathrm{Mg}^{2+}$ ions and $\mathrm{OH}^{-}$to exceed the solubility of magnesium hydroxide $\left(\mathrm{Mg}(\mathrm{OH})_{2}\right)$, favoring the formation of $\mathrm{Mg}(\mathrm{OH})_{2}$ scale:

$$
\mathrm{Mg}^{2+}+2 \mathrm{OH}^{-} \longrightarrow \mathrm{Mg}(\mathrm{OH})_{2}
$$

Then the open circuit potential of magnesium alloy has a sudden increase in the initial experiment stage, the potential offset is the largest under AC interference voltage of $5 \mathrm{~V}$, and the potential offset is the least under no AC interference. Then the open circuit potential continues to shift 

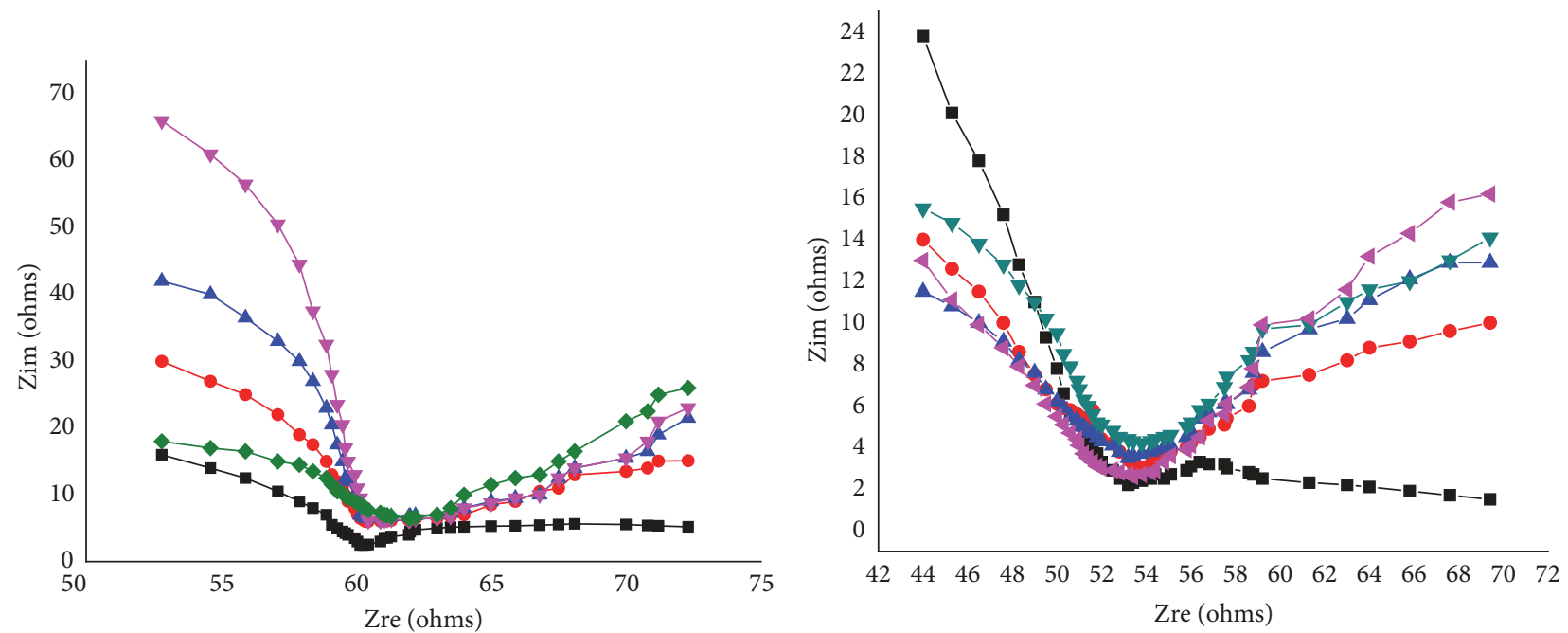

$$
\begin{aligned}
& \longrightarrow 0 \mathrm{~d} \\
& \because 2 \mathrm{~d} \\
& -\quad 4 \mathrm{~d} \\
& \square 6 \mathrm{~d} \\
& \longrightarrow \quad 8 \mathrm{~d}
\end{aligned}
$$

(a) $0 \mathrm{~V}$

$$
\begin{array}{r}
-0 \mathrm{~d} \\
-2 \mathrm{~d} \\
-\square-4 \mathrm{~d} \\
-\nabla-6 \mathrm{~d} \\
-8 \mathrm{~d}
\end{array}
$$

(b) $1 \mathrm{~V}$
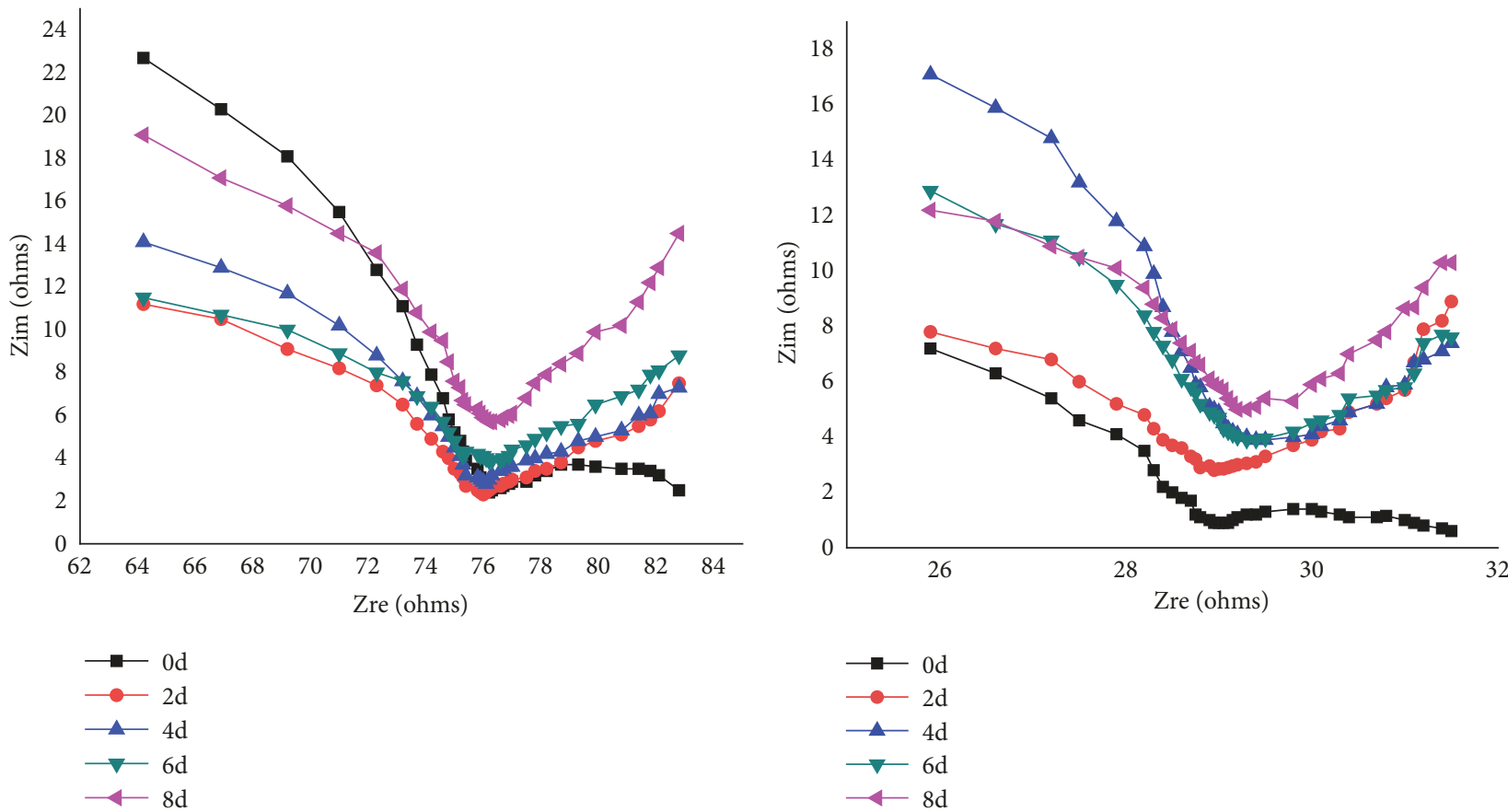

(c) $3 \mathrm{~V}$

(d) $5 \mathrm{~V}$

FIGURE 3: The EIS of magnesium sacrificial anode under different AC interference voltages at an ambient temperature of $20^{\circ} \mathrm{C}$ in the test solution.

in a positive migration, although the degree of the offset is small. It indicates that the surface corrosion is serious and the sacrificial anode surface has the largest changes because of the rapid generating of corrosion product in the first two days of the experiment. And the inclination of sacrificial anode corrosion is smaller relatively after two days of the experiment because the sacrificial anode surface is covered with corrosion products. And then the influence of the corrosion inclination of AC voltage becomes small after two days of the experiment.

In the process of corrosion and dissolution, the cathodic reaction of magnesium sacrificial anode is the oxygen absorption reaction which is mainly due to the reaction between $\mathrm{O}_{2}$ and the surface of magnesium alloy sacrificial anode. The corrosion of magnesium sacrificial anode with 


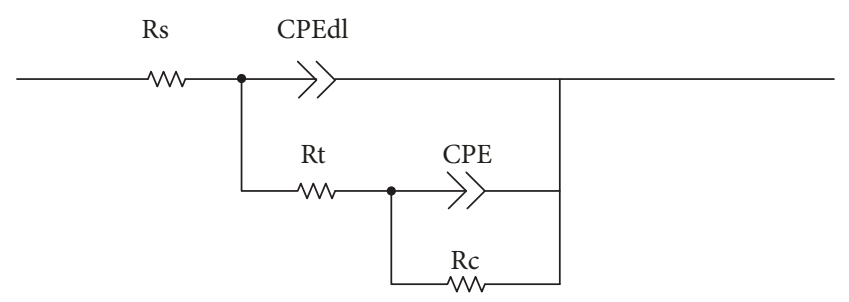

FIGURE 4: Equivalent circuit of the EIS.

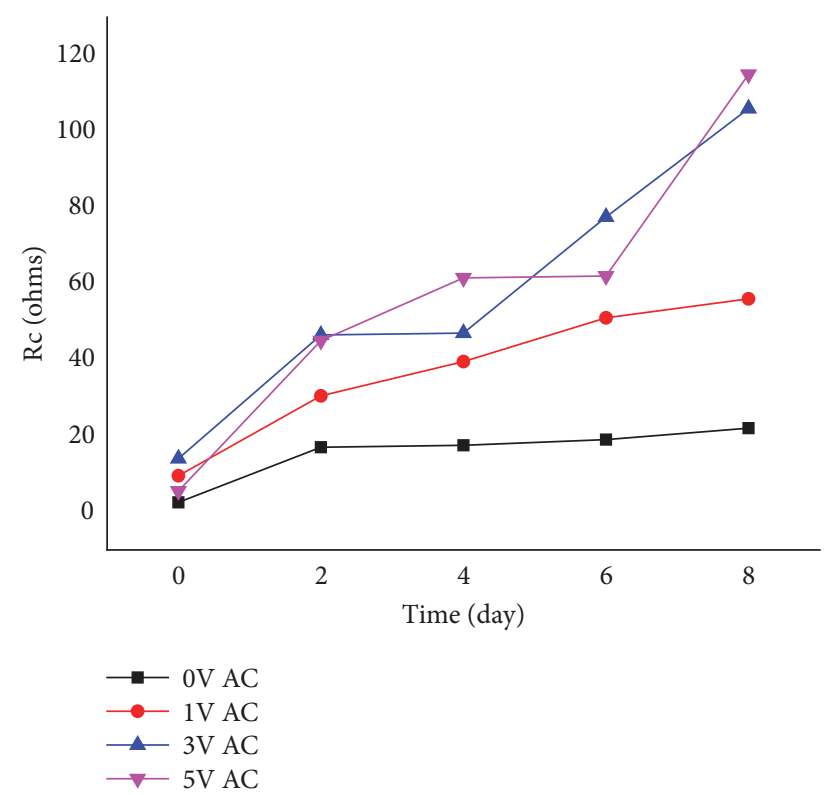

Figure 5: The Rc value of the sacrificial anode under different AC interference voltages at an ambient temperature of $20^{\circ} \mathrm{C}$ in the test solution.

AC interference is biased towards cathodic control in the first two days because the Cathodic Tafel Slope is bigger than the Anode Tafel Slope. So the diffusion rate of oxygen affects the rate of corrosion. And the stray current accelerates the transmission and diffusion of oxygen, so the corrosion rate under $\mathrm{AC}$ interference is bigger than that with no $\mathrm{AC}$ interference; the bigger the $\mathrm{AC}$ interference voltage is, the faster the corrosion rate is. In the process of experiment, the longer the time of the oxygen absorption reaction on the surface of the anode is, the more the surface corrosion products accumulate. It would be difficult for $\mathrm{O}_{2}$ to contact with the sacrificial anode surface, the reaction speed would gradually reduce and converge in all the experiments (as shown in Table 1), and the change tendency of impedance arc would be smaller (as shown in Figure 4). It indicates that the corrosion of sacrificial anode surface is relatively serious in the initial period. After that, although the corrosion is still aggravated, the rate of corrosion gradually slows down. The corrosion products on the sacrificial anode surface have accumulated very seriously, which hinders the reaction rate between $\mathrm{O}_{2}$ and sacrificial anode surface.

In the process of experiment, the corrosion products of magnesium alloy sacrificial anode would drop a little and most of the rest is attached to the surface of sacrificial anode. The corrosion products gradually accumulated and became thicker. The electrochemical impedance spectroscopy was the same mode shown in Figure 3. The corrosion products attached to the sacrificial anode surface accumulates and the resistance of the corrosion reaction becomes larger. With no $\mathrm{AC}$ interference and $\mathrm{IV} \mathrm{AC}$ interference, the increasing rate of Rc becomes slower during the experiment. It indicates that the earlier corrosion products hinder the oxygen reaction of sacrificial anode surface seriously, which makes the corrosion products increase fewer. However, the increasing rate of $\mathrm{Rc}$ becomes slower and then becomes faster during the experiment when the AC interference voltages are $3 \mathrm{~V}$ and $5 \mathrm{~V}$. It indicates that the larger AC stray current changes the corrosion state of magnesium sacrificial anode surface. There is still a great corrosion rate although the reaction resistance caused by corrosion products increases.

\section{Conclusion}

Effects of $\mathrm{AC}$ on the performance of $\mathrm{Mg}$ sacrificial anode were studied in the simulated soil solution along the apron pipeline at ambient temperature $\left(20^{\circ} \mathrm{C}\right)$. The analysis of the experimental results led to the following conclusions:

(1) AC interference is critical to the corrosion of magnesium alloy sacrificial anode. AC accelerated the dissolution of $\mathrm{Mg}$ sacrificial anode.

(2) The DC potential of Mg sacrificial shifted positively under $\mathrm{AC}$ at the same time. With the passage of time, the DC potential of the Mg sacrificial anode shifted positively in the presence or absence of AC interference, and the positive shift was more obvious in the case of AC interference than that in the absence of AC interference.

(3) As the AC interference voltage increases in the range of $0 \sim 5 \mathrm{~V}$, the corrosion rate of the sacrificial anode is faster and faster, but the corrosion inclination is weakened. Moreover, the corrosion products accumulate in the magnesium alloy sacrificial anode surface, and it affects the releasing of quantity of electric charge.

\section{Data Availability}

The research data used to support the findings of this study are included within the article.

\section{Conflicts of Interest}

The authors declare that there are no conflicts of interest regarding the publication of this article.

\section{Acknowledgments}

The research work was supported by the Central College Foundation of CAUC (3122017038) and Airport Engineering Research Base Open Fund (study on the optimization of cathodic protection model in the apron area based on BEASY). 


\section{References}

[1] D. Kuang and Y. F. Cheng, "AC corrosion at coating defect on pipelines," Corrosion, vol. 71, no. 3, pp. 267-276, 2015.

[2] L. Wang, L. Cheng, J. Li, Z. Zhu, S. Bai, and Z. Cui, "Combined effect of alternating current interference and cathodic protection on pitting corrosion and stress corrosion cracking behavior of X70 Pipeline Steel in near-neutral pH environment," Materials, vol. 11, no. 4, 2018.

[3] S. Goidanich, L. Lazzari, and M. Ormellese, "AC corrosion. Part 2: Parameters influencing corrosion rate," Corrosion Science, vol. 52, no. 3, pp. 916-922, 2010.

[4] L. Y. Xu, X. Su, and Y. F. Cheng, "Effect of alternating current on cathodic protection on pipelines," Corrosion Science, vol. 66, pp. 263-268, 2013.

[5] D.-K. Kim, S. Muralidharan, T.-H. Ha et al., "Electrochemical studies on the alternating current corrosion of mild steel under cathodic protection condition in marine environments," Electrochimica Acta, vol. 51, no. 25, pp. 5259-5267, 2006.

[6] A. Q. Fu and Y. F. Cheng, "Effect of alternating current on corrosion and effectiveness of cathodic protection of pipelines," Canadian Metallurgical Quarterly, vol. 51, no. 1, pp. 81-90, 2012.

[7] H. Zhao, P. Bian, and D. Ju, "Electrochemical performance of magnesium alloy and its application on the sea water battery," Journal of Environmental Sciences, vol. 21, no. 1, pp. S88-S91, 2009.

[8] I. A. Metwally, H. M. Al-Mandhari, A. Gastli, and Z. Nadir, "Factors affecting cathodic-protection interference," Engineering Analysis with Boundary Elements, vol. 31, no. 6, pp. 485-493, 2007.

[9] N. Kouloumbi, G. Batis, N. Kioupis, and P. Asteridis, "Study of the effect of AC-interference on the cathodic protection of a gas pipeline," Anti-Corrosion Methods and Materials, vol. 49, no. 5, pp. 335-345, 2002.

[10] S. R. Pookote and D.-T. Chin, "Effect of alternating current on the underground corrosion of steels," Materials Performance, vol. 17, no. 3, pp. 9-15, 1978.

[11] L. 1. Freiman and M. Yunovich, "Special behavior of steel cathode in soil and protection assessment of underground pipe with a buried coupon," Protection of Metals, vol. 27, pp. 437-447, 1991.

[12] D. Tang, Y. Du, M. Lu, L. Dong, and Z. Jiang, "Progress in the mutual effects between AC interference and the cathodic protection of buried pipelines," Journal of the Chinese Society of Corrosion and Protection, vol. 33, no. 5, pp. 351-356, 2013.

[13] H. Bruckner W, "Electrochemical methods for the study of corrosion lead- encased water pipe and cables," Corrosion, vol. 8, pp. 135-136, 1965.

[14] D. Tang, Y. Du, X. Li, Y. Liang, and M. Lu, "Effect of alternating current on the performance of magnesium sacrificial anode," Materials and Corrosion, vol. 93, pp. 133-145, 2016.

[15] K. Yin H, M. Tang H, and J. Xiong X, "Corrosion of buried steel structure under effect of electrical field with industry frequency," Journal of Chinese Society for Corrosion and protection, vol. 2, no. 3, pp. 33-41, 1982.

[16] X. Wang, G. Yang, H. Huang, Z. Chen, and L. Wang, "Study on AC stray current corrosion law of buried steel pipelines," Applied Mechanics and Materials, vol. 263-266, no. 1, pp. 448451, 2013.

[17] M. Ormellese, S. Goidanich, and L. Lazzari, "Effect of AC interference on cathodic protection monitoring," Corrosion
Engineering, Science and Technology, vol. 46, no. 5, pp. 618-623, 2011.

[18] Y. T. Li, X. Li, G. W. Cai, and L. H. Yang, "Influence of AC interference to corrosion of Q235 carbon steel," Corrosion Engineering, Science and Technology, vol. 48, no. 5, pp. 322-326, 2013.

[19] A. Q. Fu and Y. F. Cheng, "Effects of alternating current on corrosion of a coated pipeline steel in a chloride-containing carbonate/bicarbonate solution," Corrosion Science, vol. 52, no. 2, pp. 612-619, 2010.

[20] D. Kuang and Y. F. Cheng, "Effects of alternating current interference on cathodic protection potential and its effectiveness for corrosion protection of pipelines," Corrosion Engineering, Science and Technology, vol. 52, no. 1, pp. 22-28, 2017.

[21] M. Büchler and H.-G. Schöneich, "Investigation of alternating current corrosion of cathodically protected pipelines: Development of a detection method, mitigation measures, and a model for the mechanism," Corrosion, vol. 65, no. 9, pp. 578-586, 2009. 


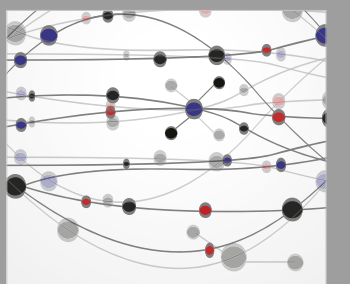

The Scientific World Journal
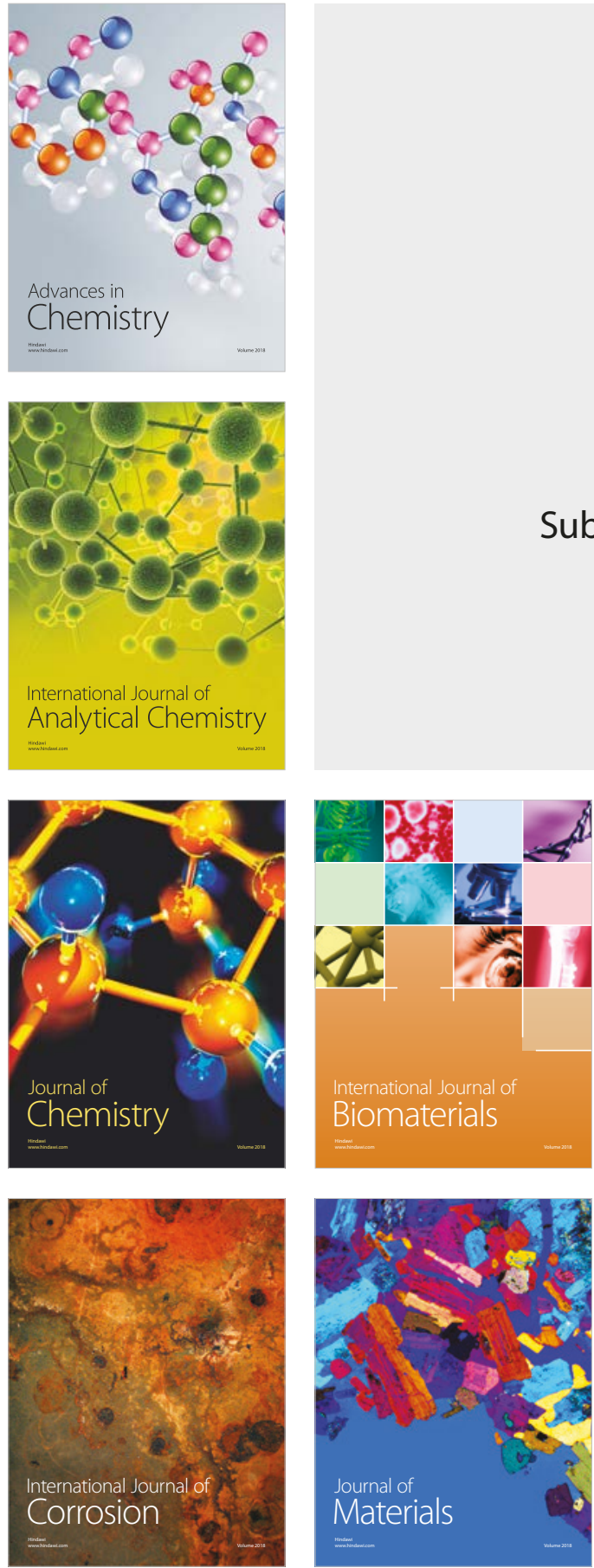

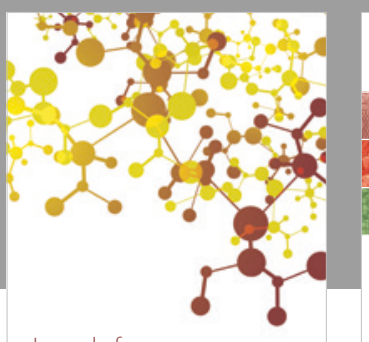

Journal of

Applied Chemistry
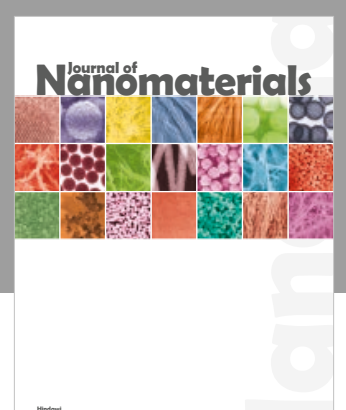

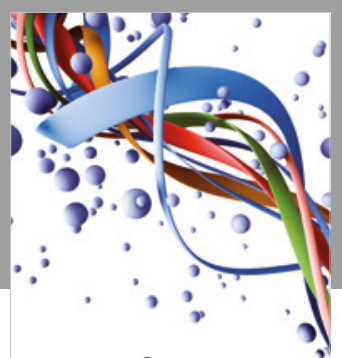

Scientifica

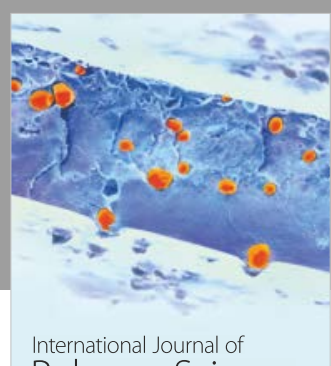

Polymer Science

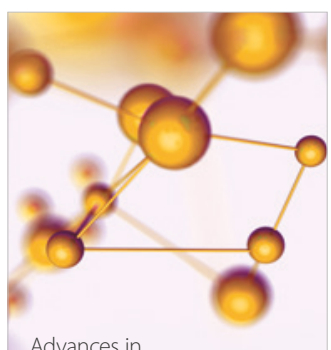

Physical Chemistry
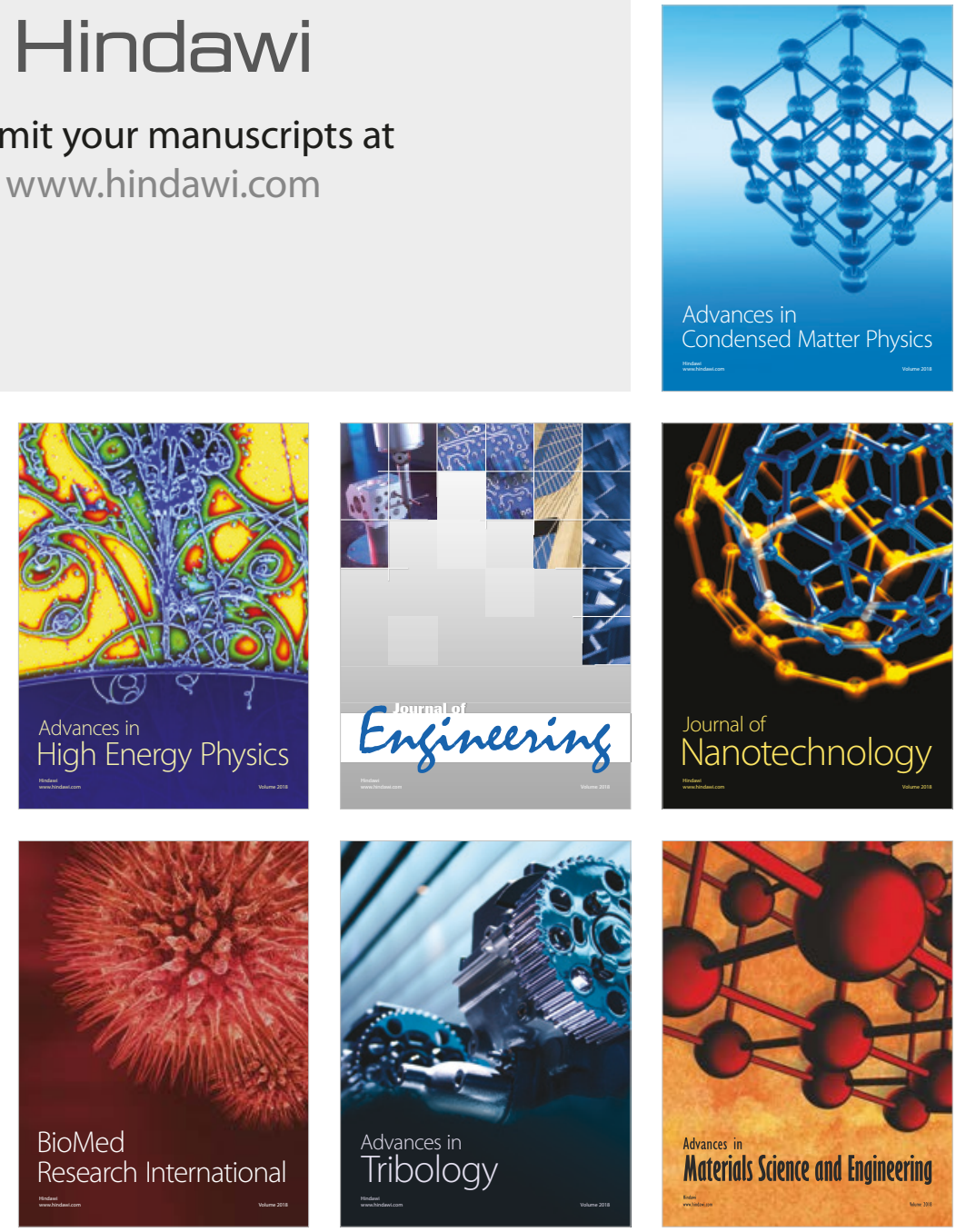